\title{
Nursing Students' Health Literacy Level and Health Practices: a Cross Sectional Study at a University in Namibia
}

Takaedza Munangatire ( $\square$ takamunangatire@gmail.com )

University of Namibia

Nestor Tomas

University of Namibia

Violetha Mareka

University of Namibia

\section{Research Article}

Keywords: health literacy, health practices, nursing students

Posted Date: February 15th, 2021

DOI: https://doi.org/10.21203/rs.3.rs-192225/v1

License: (c) (i) This work is licensed under a Creative Commons Attribution 4.0 International License.

Read Full License 


\section{Abstract}

Background: Inadequate health literacy and poor health practices among nurses could be a hindrance to empowering the population with good health practices. For the nurses to empower the population, they need to be equipped with good health literacy and good health practices. The starting point of solving this problem is through provision of deliberate health literacy and health practice education in the nursing curriculum. This study explored health literacy level and health practices of nursing students in Namibia. Specifically the study examined the health literacy level, health practices and the relationship between the two among nursing students across four levels of study.

Methods: A descriptive cross-sectional study was carried out among 205 nursing students. A simple random stratified sampling method was used and data were collected using questionnaire for health literacy (16 items) and health practices (11 items. Pearson correlation, independent t-test and One-way ANOVA were used to analyse the data.

Results: The overall mean general health literacy score was $13.04 \pm 1.52$. The majority $(n=157 ; 76.5 \%)$ of the students were found to have adequate health literacy scores, $21.5 \%$ with moderate health literacy scores and only $2 \%$ with inadequate health literacy scores. The overall mean health practice score was $32.4 \pm 5.50$. Most $(n=106 ; 51.7 \%)$ of the students were found to have poor health practices, $44.4 \%$ had average health practices and $3.9 \%$ had good health practices. There was no significant relationship between health literacy levels and health practices of the students $(p=0.63)$.

Conclusions: Nursing students have good health literacy but more efforts should be applied to maintain such health literacy levels during and beyond the point of graduation. However, with poor health practices, there is need to investigate more on the contributing factors and develop strategies that can support good health practices among nursing students and maybe these can be transferred into their professional careers as nurses.

\section{Background}

Health literacy is the extent to which individuals are motivated to apply cognitive and social skills to obtain, comprehend and utilise health information in a manner that improves health status [1]. The concept of health literacy goes beyond general literacy, as educated people have been found to have poor health literacy levels [2]. This applies to health care workers such as nurses who are themselves expected to have good health literacy levels and pass it on to their patients [3]. However, globally health literacy levels have been found to be inadequate [1]. Specifically, many studies have demonstrated that nursing professionals do not possess the required levels of health literacy $[4,5,6]$.

In the context of health care, health literacy is important for a number of reasons. Health literacy determines how people make decisions about their health [7]. Individuals with good health literacy have a better understanding of their health and are likely to have good health outcomes [8]. Among the health determinants such as income, employment status, and education level, health literacy is one of the most 
significant determinant of an individual's health status [9]. Therefore, health care professionals require health literacy skills because they have the responsibilities to assist the patients develop health literacy skills $[3,10]$. However, insufficient training on health literacy among health care professionals has contributed to low health literacy level and poor health practices among health care workers [11]. Resultantly it is necessary that nursing education support the development of health literacy and good health practice [12].

Good health outcomes can only be attained if there is good health practices among the population. These practices include diet, exercises, health-seeking behaviour, sleeping patterns, compliance with treatment inter alia. A number of studies have reported on the health practices of nursing students. In one-study students' health, practices were classified at the medium level [13]. In another study, the majority of students $120(85.7 \%)$ had medium nutritional habits [4]. However others studies revealed that students displayed good diets practices, exercise and sleeping patterns (7.18 on a scale of 0 to 10) [15].

Current evidence strongly suggest that health literacy level is generally low globally and is cause for concern for health care authorities $[1,9]$. The responsibility of improving health literacy among individuals lies with health care workers, with nurses having a role of educating patients and the community on health literacy and practices $[8,16]$. It is expected that nursing education programmes should develop health literacy skills among nursing students and improve their health practices before graduating [10]. If health literacy skills are not developed while at nursing schools, nursing students may graduate as nurses lacking the required skills to improve health literacy. Several studies indicate that health literacy levels are not sufficient in both nursing students and nurses; hence, it is necessary to integrate health literacy in undergraduate curriculum and in professional development courses $[17,18$; 19].

Existing evidence shed light into the state of health literacy among nursing students globally. One study on the health literacy levels of 808 nursing students at a university found that about $50 \%$ of the students had adequate health literacy levels without indicating if health literacy education was part of the curriculum [26]. The results suggested that gender, age and year in education influenced the health literacy levels of the nursing students [26]. In another study, among 845 undergraduate nursing students showed that the students' health literacy levels changed as they progressed through their nursing education programme [27].

Other studies revealed that the health literacy levels of nursing students were not adequate $[18,28]$. One study investigated the health literacy and behaviour related to health among nursing students and their results indicated that only $37.3 \%(n=337$ of the respondents had adequate health literacy [25]. The study reported that health literacy was a predictor of health related behaviour among the nursing students [25]. Similarly, a study among 160 senior undergraduate students revealed that about $31.35 \%$ of students had acceptable health literacy levels although there was no significant relationship between the literacy scores and the experience of health literacy. [18]. 
On the contrary, two separate studies reported that t nursing students had sufficient health literacy levels $[10 ; 29]$. In an investigation of the health literacy levels and affecting factors, the health literacy levels were rated high with the fourth year nursing students scoring highest from 303 respondents [10]. Similarly, in a study on health literacy among health and social care university students, it was found that $69 \%(n=52)$ of the nursing students had adequate health literacy knowledge which was higher than the score for social care students [29]. According to these studies, the literacy levels of nursing students differed from place to place. In addition, these studies showed that the relationship between nursing students' health literacy levels and their health practice was inconclusive.

Addressing the problem of health literacy globally should start with nursing education that develops health literacy skills of nursing student [20]. Currently not all nursing education programmes include a health literacy component in the curriculum. Without deliberate health literacy education, it is necessary to assess the effects of nursing education on students' health literacy and practice [19]. However, it is a concern that nurse educators do not measure how their training programmes support development of health literacy among their students [10]. Subsequently, there is need for evidence to ascertain the impact of education on the health literacy and health practices of nursing students.

Low levels of health literacy are associated with poor self-care and quality of life [21]. In addition, people with low health literacy levels do little to promote their health, use health services, and adhere to treatments [22, 23]. Health inequalities have been found to be high in communities with poor health literacy levels [24]. Further evidence suggests that people with inadequate health literacy are likely to engage in risk health behaviours [25]. Therefore, it is important that efforts be directed towards raising the health literacy levels of health care professionals in particular nurses who form the majority of the health care workforce globally and spent more time with patients than any other professionals.

There is evidence suggesting that incorporating health literacy in the nursing curriculum can improve health literacy levels among nurses $[8,30]$. However, health literacy is not explicitly part of the nursing curriculum in Namibia and many other countries; therefore, evidence is needed to determine if current nursing education programmes are adequately equipping students with the required health literacy skills. It is important to monitor and assesse the health literacy levels of nursing students [27]. The study specifically assessed the students' health literacy levels, their practices and compared how these variables differ across the four years of undergraduate nursing education. This study expanded our understanding of how nursing education can influence nursing students' health literacy and health practices in different years of study. No existing studies have compared the health literacy and practices in different groups of students in a nursing program.

\section{Materials And Methods}

\section{Study Design and Sample}


A descriptive cross-sectional study was conducted between March and June 2020 with 205 nursing students from a university in Namibia. A simple random stratified sampling method was used for the selection of sample of 205 nursing students (from four groups of students, year one to year four who voluntarily participated in the study. The students were informed in the cover letter that their responses were anonymously populated and confidentiality was assured, as data was only accessible to the researchers.

\section{Research questions}

The research questions were;

1. What is the health literacy level of nursing students in different years of a nursing programme?

2. What are the health practices of nursing students in different years of a nursing programme?

3. What is the relationship between nursing students' health literacy levels and their health practices?

4. What are the determinants of the health literacy and practices of nursing students?

\section{Data collection tool}

The researchers prepared the questionnaire using literature; Health literacy Knowledge and Experiences Survey (HL-KES), Test of Functional Health Literacy for Adults (TOFHLA), Turkish Health Literacy scale 32(THL-32) and lastly the five point Likert scale (TSOY-32). The questionnaire consisted of items asking students' socio-demographic data including age, gender, marital status, source of income, prior qualification, year of study and weather they had a chronic disease or not. The questionnaire then assessed students' health literacy levels using 16 items and evaluated their health practices using 11 questions.

The 16 health literacy items were scored using a Yes or No to measure the health literacy levels the health practice items used a five point Likert scale to measure degree of compliance with health practices ranging from $1=$ Never to $5=$ always. The health literacy scores were obtained by adding up the items score with a maximum of 16 for health literacy level and a maximum score of 55 for health practice. Then the following classification was used to categorise the health literacy level; adequate literacy level (13-16); Moderate literacy level (9-12); inadequate literacy level (0-8) and for health practices; Good health practices (44-55); Moderate health practices (33-43); Poor health practices (11-32).

The reliability scores showed that the Cronbach's alpha value for the whole questionnaire was found to be 0.75 , for the literacy domain was 0.760 and for the health practice domain as 0.72 .

\section{Data analysis}

The researchers analysed the data using the SPSS 26.0 program. The frequencies, percentage. Mean and standard deviation (mean \pm SD) were computed for age, health literacy levels and health practices were computed as descriptive statistics. Pearson correlation was used to analyse the relationship between age and health literacy levels and health practices. Independent $t$ test was used to determine the differences in health literacy levels and health practices for the different groups according to gender, sexual activity 
and chronic disease status. One-way ANOVA test was used in comparison of the mean $\mathrm{HL}$ level and health practices scores for the four different groups based on their year of study.

\section{Results}

\section{Sample characteristics}

The mean age of the participants was $22.73 \pm 5.691 .75 ; 55.0 \%$ of them were male; $92.8 \%$ of them were married. $64.9 \%$ of the participants were sexually active; $81.0 \%$ of them got their financial support from parents, $92.9 \%$ had no chronic disease, $89.9 \%$ of them had no prior tertiary level qualification. $23.9 \%$ of the participants were first year students, $26.3 \%$ of them were second year students, $27.3 \%$ of them were third year students and 22.45 were fourth year students.

\section{Health literacy}

The overall mean general health literacy score was $13.04 \pm 1.52$. The mean health literacy score for first year students was $12 \pm 1.79$, second year students was $12.98 \pm 1.49$, third year students was $13.54 \pm 1.18$ and for fourth year students was $13.07 \pm 1.45$. The mean health literacy scores for third and fourth year students were higher than the overall mean health literacy. (Table 1$)$. The majority $(n=157 ; 76.5 \%)$ of the students were found to have adequate health literacy scores, $21.5 \%$ with moderate health literacy scores and only $2 \%$ with inadequate health literacy scores. (Table 2 )

Table 1

Health literacy scores by year of study

\begin{tabular}{|llll|}
\hline Year of study & $\mathbf{n}(\%)$ & Mean & SD \\
\hline First year & 49 & 12.53 & 1.79 \\
\hline Second year & 54 & 12.98 & 1.49 \\
\hline Third year & 56 & 13.54 & 1.18 \\
\hline Fourth year & 46 & 13.07 & 1.45 \\
\hline Total & $\mathbf{2 0 5}$ & $\mathbf{1 3 . 0 4}$ & $\mathbf{1 . 5 2}$ \\
\hline
\end{tabular}


Table 2

Health literacy score categories

\begin{tabular}{|lll|}
\hline Health literacy score category & $\mathbf{n}$ & $\mathbf{\%}$ \\
\hline Inadequate $(0-8)$ & 4 & 2.0 \\
\hline Moderate $(9-12)$ & 44 & 21.5 \\
\hline Adequate $(13-16)$ & 157 & 76.5 \\
\hline Total & $\mathbf{2 0 5}$ & $\mathbf{1 0 0}$ \\
\hline
\end{tabular}

\section{Health practices}

The overall mean health practice score was $32.4 \pm 5.50$. The mean health practice score for first year students was $31.6 \pm 5.13$, second year students was $31.9 \pm 5.67$, third year students was $32.7 \pm 5.05$ and for fourth year students was $33.2 \pm 6.16$. The mean health practice scores for third and fourth year students were higher than the overall mean health literacy. (Table 3$)$. Most $(n=106 ; 51.7 \%)$ of the students were found to have poor health practices, $44.4 \%$ had average health practices and $3.9 \%$ had good health practices. (Table 4).

Table 3

Health practices scores

\begin{tabular}{|llll|}
\hline Year of study & $\mathbf{n}(\%)$ & Mean & SD \\
\hline First year & 49 & 31.6 & 5.13 \\
\hline Second year & 54 & 31.9 & 5.67 \\
\hline Third year & 56 & 32.7 & 5.05 \\
\hline Fourth year & 46 & 33.2 & 6.16 \\
\hline Total & $\mathbf{2 0 5}$ & $\mathbf{3 2 . 4}$ & $\mathbf{5 . 5 0}$ \\
\hline
\end{tabular}

Table 4

Health practices categories

\begin{tabular}{|lll|}
\hline Health practices category & $\mathbf{n}$ & $\mathbf{\%}$ \\
\hline Poor & 106 & 51.7 \\
\hline Average & 91 & 44.4 \\
\hline Good & 8 & 3.9 \\
\hline Total & $\mathbf{2 0 5}$ & $\mathbf{1 0 0}$ \\
\hline
\end{tabular}




\section{Correlations}

There was no significant relationship between health literacy levels and health practices of the students $(r=0.033, p=0638)$. The Pearson correlations showed that there were no significant correlation between health literacy of the students and age $(r=0.091, p=0.196)$ while the Pearson correlation between health practice and age was significant with a low positive relationship $(r=0.364, p=0.000)$.

\section{Independent t-tests}

No significant differences were found oh health literacy scores for the male and female groups, sexually and active and non-sexually active and the chronic and non-chronic disease groups (Table 5).

The independent t-tests showed that there was a significant difference between the mean scores of female and male participants on health practices $(p=.000) \mathrm{Cl}[5.2,2.318]$. There was also a significant difference between the mean scores of the sexually active group and the non-sexually active group $(p=$ 000), $\mathrm{Cl}[1.823,4.933]$ (Table 5). 
Table 5

Independent $t$ test for health literacy and health practices among the groups

\begin{tabular}{|c|c|c|c|c|}
\hline \multicolumn{5}{|l|}{ Health literacy } \\
\hline & Mean(SD) & \multicolumn{2}{|l|}{$\mathrm{p}$ value } & Confidence Intervals \\
\hline \multicolumn{5}{|l|}{ Gender } \\
\hline Male & $13.21(1.40)$ & \multirow{2}{*}{\multicolumn{2}{|c|}{0.161}} & \multirow[t]{2}{*}{$-0.72,0.12$} \\
\hline Female & $12.91(1.59)$ & & & \\
\hline \multicolumn{5}{|l|}{ Sexual activity } \\
\hline Sexually active & $13.05(1.53)$ & \multirow{2}{*}{\multicolumn{2}{|c|}{0.873}} & \multirow[t]{2}{*}{$-0.41,0.48$} \\
\hline Not sexually active & $13.01(1.50)$ & & & \\
\hline \multicolumn{5}{|c|}{ Chronic disease status } \\
\hline Chronic disease & $13.68(1.11)$ & \multirow{2}{*}{\multicolumn{2}{|c|}{0.747}} & \multirow[t]{2}{*}{$-2.18,-3.03$} \\
\hline No chronic disease & $12.98(1.54)$ & & & \\
\hline \multicolumn{5}{|l|}{ Health practice } \\
\hline & Mean(SD) & \multicolumn{2}{|l|}{$\mathrm{p}$ value } & Confidence Intervals \\
\hline \multicolumn{5}{|l|}{ Gender } \\
\hline Male & $30.72(4.81)$ & & \multirow[t]{2}{*}{0.000} & \multirow[t]{2}{*}{$-5.20,-2.32$} \\
\hline Female & $34.48(5.64)$ & & & \\
\hline \multicolumn{5}{|l|}{ Sexual activity } \\
\hline Sexually active & $33.45(4.95)$ & & \multirow[t]{2}{*}{0.000} & \multirow[t]{2}{*}{$1.82,4.93$} \\
\hline Not sexually active & $30.07(5.92)$ & & & \\
\hline \multicolumn{5}{|c|}{ Chronic disease status } \\
\hline Chronic disease & $32.79(6.16)$ & & \multirow[t]{2}{*}{0.055} & \multirow[t]{2}{*}{$-0.02,-1.42$} \\
\hline No chronic disease & $32.36(5.42)$ & & & \\
\hline
\end{tabular}

\section{One-way ANOVA}

The ANOVA for the four groups showed that there was no significant difference on the mean health practice scores but there was a significant difference on the mean health literacy levels $(p=0.008)$. Please see Table 6 below. 
Table 6

ANOVA on health literacy and health practice scores among the different groups of nursing students

\begin{tabular}{|c|c|c|c|}
\hline \multicolumn{4}{|l|}{ Health literacy } \\
\hline Level of study & Mean(SD) & 95\% Confidence Interval for Mean & $\mathrm{p}$ value \\
\hline First year & $12.53(1.79)$ & $12.02,13.05$ & \multirow[t]{5}{*}{0.008} \\
\hline Second year & 12.98(1.49) & $12.58,13.39$ & \\
\hline Third year & 13.54(1.18) & $13.22,13.85$ & \\
\hline Fourth year & 13.07(1.45) & $12.63,13.50$ & \\
\hline Total & 13.04(1.51) & $12.84,13.25$ & \\
\hline \multicolumn{4}{|l|}{ Health practices } \\
\hline Level of study & Mean(SD) & 95\% Confidence Interval for Mean & $\mathrm{p}$ value \\
\hline First year & $31.61(5.14)$ & $30.14,33.09$ & \multirow[t]{5}{*}{0.462} \\
\hline Second year & $31.93(5.69)$ & $30.37,33.48$ & \\
\hline Third year & $32.71(5.05)$ & $31.36,34.07$ & \\
\hline Fourth year & $33.22(6.16)$ & $31.39,35.05$ & \\
\hline Total & $32.36(5.50)$ & & \\
\hline
\end{tabular}

\section{Discussion}

\section{Health literacy level}

The study found that the overall health literacy levels were moderate $(21.5 \%)$ to adequate $(76.5 \%,(n=$ 205). This is a higher percentage than found in many other studies, $69 \%(n=52)$ of the nursing students had adequate health literacy knowledge [29] $50 \%(n=808)$ of the students had adequate health literacy levels [26]. Other studies had even lower health literacy levels; $41.7 \%(n=283)$ [31]; 37.3\% $(n=337)$ of the nursing students had adequate health literacy [25], 31.35\% $(n=160)$ of students had acceptable health literacy levels. The high health literacy levels in this study could suggest that the curriculum is adequately equipping nursing students with health literacy knowledge.

\section{Health practices}

The study found that the health practices of the nursing students were poor, with poor diet, poor exercises practices and health seeking behaviours inter alia. It is unclear why the students had poor health habits. Our results differed from other findings, which showed that the health practices of students were moderate to high, for example, it was reported that the healthy lifestyle behaviours of nursing students were moderate in two studies [13,32]. Other studies reported even better health practices such as [14] 
results which showed that the nursing students $86.6 \%$ of the fair to good nutritional habits and [15] indicating a rating of 7.18 using a scale from 0 to 10 (0 being poor health and 10 excellent).

\section{Relationship between health literacy and health practices}

In this study, there was no significant correlation between health literacy and health practices. The health literacy was generally high but the health practices were generally poor. The high health literacy could be explained by the fact that the respondents are nursing students and they learn about health. However, the practice, not being part of the curriculum requirements depends on general health behaviour of individuals. Our findings in contradiction to literature. Studies have shown that there is a significant relationship between the literacy scores and the experience of health literacy $[18,25]$. Evidence also suggested people with poor health literacy that have poor health practices such as lack of health promotion and non-adherence to treatments [22]. However, in this study the nursing students despite their adequate health literacy; they lacked health promotion, treatment adherence and health eating practices. Health literacy alone cannot predict health practices; other factors should be considered. One can be aware of what good health should be but may lack the resources or find themselves in circumstances where it is difficult to do so.

\section{Determinants of health literacy and health practice}

An analysis of the characteristic of the nursing students and the health; literacy levels showed that only age was significantly correlated to the health literacy scores. Gender, marital status and chronic disease status were not correlated to health literacy. Previous studies confirm that age significantly influences health literacy [33] and confirms that gender do not determine the level of health literacy [31] as well as having a chronic disease or not [33]. However, gender has been found to show differences in health literacy levels among nursing students [26]. Students with chronic diseases showed higher levels of health literacy compared to those without [10]. Our results should be interpreted with caution because most nursing students are young and not prone to chronic

\section{Health literacy per year of study}

The study showed that there was significant difference $(p<0.05)$ in the average literacy levels scores across the years of study from first year to fourth year nursing students. Our findings are in confirm results reported in the literature with fourth year nursing students having significantly higher mean health literacy scores compared to first year nursing students $(p<0.05)(10)$. Furthermore, our results were inconsistent with the findings of $[31,34]$ whose results showed that the difference in health literacy mean scores and student years were statistically significant. Our results should could be explained by the lack of specific health literacy content in the nursing curriculum leaving development of health literacy knowledge to chance, hence not uniform across levels of study.

\section{Health practice per year of study}

The study results reported that the health practices were not significantly different across the four years of nursing student. This in contrast to other results. Final year nursing students showed significantly 
higher self-related health than the first year students [33] did. As students progressed in their nursing studies, they showed improved health practices including more exercises and dietary practices [35]. The lack of emphasis on self-care among nursing students could explain poor health practices in our study.

\section{Implications of the study's findings}

It is important for nursing students to be aware of their health literacy and practices from year one up to final year of study with a focus on improving the literacy and practice. The nurse educators should equally monitor students' health literacy and practices during the nursing education programme to make sure that the curriculum supports development of good health literacy and practices among nursing students. Efforts should be made to ensure that students understand the importance of health literacy and practice for them and for their future patients when they become professional nurses. This needs a comprehensive deliberate approach to include health literacy and practice in the curriculum and make it part of the major assessments.

\section{Strengths And Limitations}

The strength of this study is that it exposed the effects of the current nursing curriculum in Namibia on the student nurses' health literacy and practice. By comparing the literacy levels and practices among students in different years, the study helped to show the little effect the curriculum is having on the students' health literacy. In addition, by comparing health literacy scores with health practices, the study highlighted that knowledge does not necessarily translate to practice.

The major limitation of the study is that it was conducted at one satellite university campus, expanding the study to the whole university and other universities in Namibia can strengthen the arguments presented in this study. Furthermore, the study was a cross sectional study, prospective studies could have been better in tacking the pattern of changes in health literacy practices among the students from the time they enter the nursing programme to the time they graduate.

\section{Conclusion}

Nursing students have good health literacy but more efforts should be applied to maintain such health literacy levels during and beyond the point of graduation. However, with poor health practices, there is need to investigate more on the contributing factors and develop curriculum strategies that can support good health practices among nursing students. Good literacy levels not supported by good health practices among nursing students sends double messages to their patients making the transfer of health literacy and practice ineffective. As age was found to be a determinant of health practices, it is important to support young students more in adopting good health practices as well as investigate what is it about age that makes people more health conscious, as they grow older 


\section{Declarations}

\section{Ethics approval and consent to participate}

The study was conducted according to the Declaration of Helsinki respecting all ethical principles. The School of Nursing Ethical Committee of the University of Namibia (SoNEC 19/2020) granted ethical approval and permission. Every participant was provided with written and verbal information about the purpose of the study by the researchers. Informed consent was obtained from all participants. The participants were also were informed that participation was voluntary, and they could withdraw at any time without any prejudice or loss. Confidentiality and anonymity was ensured through use of nonidentifiable electronic questionnaire.

\section{Consent for publication}

Not applicable

\section{Availability of data and materials}

The datasets generated and/or analysed during the current study are not publicly available due to the respect of participants privacy but are available from the corresponding author on reasonable request and approval by the School of Nursing Ethical Committee of the University of Namibia

\section{Competing interests}

The authors declare that they have no competing interests" in this section.

\section{Funding}

Not applicable

\section{Authors' contributions}

Authors' contributions TM and VM participated in the design of the study, handled the collection of data and management of data. TM and NT performed the statistical analysis. VM drafted the first version of the manuscript, assisted by TM and NT. Further revisions focusing on interpreting the data, results, and the discussion were written in an iterative process that included all authors. All authors critically revised the text, read, and approved the article before submission.

\section{Acknowledgements}

No applicable

\section{References}


1. Sørensen K, Van den Broucke S, Fullam J, Doyle G, Pelikan J, Slonska Z, et al. Health literacy and public health: a systematic review and integration of definitions and models. BMC Public Health. 2012 Dec; 12(1):1-3. doi: 10.1186/1471-2458-12-80

2. Karl JI, McDaniel JC. Health literacy deficits found among educated, insured university employees. Workplace health \& safety. 2018 Sep;66(9):419-27.doi.10.1177/2165079918758773

3. Elsborg L, Krossdal F, Kayser L. Health literacy among Danish university students enrolled in healthrelated study programmes. Scandinavian journal of public health. 2017 Dec;45(8):831-8. org/10.1177/1403494817733356

4. Zhang Y, Zhang F, Hu P, Huang W, Lu L, Bai R, Sharma M, Zhao Y. Exploring health literacy in medical university students of Chongqing, China: a cross-sectional study. PloS one. $2016 \mathrm{Apr}$ 6;11(4):e0152547. org/10.1371/journal.pone.0152547

5. Mather $C$, Douglas $T$, Jacques A. Health literacy of undergraduate health profession students in Australia: a comparison of the island State of Tasmania and Other Australian universities. Kontakt. 2018 Dec 1; 20(4):e386-93. 10.1016/J.KONTAKT.2018.08.008 (doi.org)

6. Vamos, S., Yeung, P., Bruckermann, T., Moselen, E. F., Dixon, R., Osborne, R. H., ... \& Stringer, D. (2016). Exploring health literacy profiles of Texas university students. Health Behavior and Policy Review, 3(3), 209-225.

7. Brabers AE, Rademakers JJ, Groenewegen PP, Van Dijk L, De Jong JD. What role does health literacy play in patients' involvement in medical decision-making?. PloS one. $2017 \mathrm{Mar}$ 3;12(3):e0173316.org/10.1371/journal.pone.0173316

8. Mosley CM, Taylor BJ. Integration of health literacy content into nursing curriculum utilizing the health literacy expanded model. Teaching and Learning in Nursing. 2017 Apr 1;12(2):109-16.Elsevier Ltd. Retrieved December 7, 2020 from https://www.learntechlib.org/p/198648/.

9. Güner MD, Ekmekci PE. Health literacy level of casting factory workers and its relationship with occupational health and safety training. Workplace health \& safety. 2019 Sep;67(9):452-60. org/10.1177/2165079919843306

10. Ayaz-Alkaya S, Terzi H. Investigation of health literacy and affecting factors of nursing students. Nurse Education in Practice. 2019 Jan 1;34:31-5. org/10.1016/j.nepr.2018.10.009

11. Coleman CA, Hudson S, Maine LL. Health literacy practices and educational competencies for health professionals: a consensus study. Journal of health communication. 2013 Dec 4;18(sup1):82-102. org/10.1080/10810730.2013.829538

12. Budhathoki SS, Pokharel PK, Good S, Limbu S, Bhattachan M, Osborne RH. The potential of health literacy to address the health related UN sustainable development goal 3 (SDG3) in Nepal: a rapid review. BMC health services research. 2017 Dec;17(1):1-3. https://doi.org/10.1186/s12913-017-21836

13. Polat Ü, Özen Ş, Kahraman BB, Bostanoğlu H. Factors affecting health-promoting behaviors in nursing students at a university in Turkey. Journal of Transcultural Nursing. 2016 Jul;27(4):413-9. org/10.1177/1043659615569536 
14. Bashatah A. Nutritional habits among nursing students using Moore Index for Nutrition Self Care: A cross-sectional study from the nursing school Riyadh, Saudi Arabia. Nursing open. 2020 Nov;7(6):1846-51. https://doi.org/10.1002/nop2.572

15. Nevins CM, Sherman J. Self-care practices of baccalaureate nursing students. Journal of Holistic Nursing. 2016 Jun;34(2):185-92. org/10.1177/0898010115596432

16. Smith CA, Chang E, Gallego G, Balneaves LG. An education intervention to improve health literacy and decision making about supporting self-care among older Australians: a study protocol for a randomised controlled trial. Trials. 2017 Dec;18(1):1-8. doi.org/10.1186/s13063-017-2182-2

17. Okuyan CB. Investigation of Health Literacy Levels and Health Perceptions of Nursing Students: A Cross-sectional study. International Journal of Caring Sciences. 2019 Jan;12(1):270.

18. Maduramente TS, Orendez JD, Saculo JA, Trinidad AL, Oducado RM. Health literacy: Knowledge and experience among senior students in a nursing college. Indonesian Nursing Journal of Education and Clinic (INJEC). 2019;4(1):9-19. org/10.24990/injec.v4i1.227.

19. Alsubaie MS, Salem OA. Nursesâ Perception of Health Literacy. Annals of Medical and Health Sciences Research. 2019.

20. Nantsupawat A, Wichaikhum OA, Abhicharttibutra K, Kunaviktikul W, Nurumal MS, Poghosyan L. Nurses' knowledge of health literacy, communication techniques, and barriers to the implementation of health literacy programs: A cross-sectional study. Nursing \& health sciences. 2020 Sep;22(3):57785. org/10.1111/nhs. 12698

21. Macabasco-O'Connell A, Fry-Bowers EK. Knowledge and perceptions of health literacy among nursing professionals. Journal of Health Communication. 2011 Sep 30;16(sup3):295-307. doi: 10.1080/10810730.2011.604389

22. Lee HY, Rhee TG, Kim NK, Ahluwalia JS. Health literacy as a social determinant of health in Asian American immigrants: findings from a population-based survey in California. Journal of general internal medicine. 2015 Aug;30(8):1118-24. org/10.1007/s11606-015-3217-6

23. Smith JA, Ireland S. Towards equity and health literacy. Health promotion journal of Australia: official journal of Australian Association of Health Promotion Professionals. 2020 Jan;31(1):3.

24. Protheroe J, Whittle R, Bartlam B, Estacio EV, Clark L, Kurth J. Health literacy, associated lifestyle and demographic factors in adult population of an English city: a cross-sectional survey. Health Expectations. 2017 Feb;20(1):112-9. org/10.1111/hex.12440

25. Kolnik TŠ, Hozjan D, Babnik K. Health literacy and health related lifestyle among nursing students. Pielegniarstwo XXI wieku/Nursing in the 21st Century. 2017 Jun 1;16(2):42-6. doi: 10.1515/pielxxiw2017-0017

26. Ozkaya B. Investigation of health literacy levels of nursing students and affecting factors. International Journal of Caring Sciences. 2019;12(1):270-9.

27. Balmer D, King A, Moloney W, Moselen E, Dixon R. Nursing students and health literacy: The effect of region and programme level. Nurse education in practice. 2020 Jan 1;42:102688. doi: 10.1016/j.nepr.2019.102688. 
28. Mullan J, Burns P, Weston K, McLennan P, Rich W, Crowther S, Mansfield K, Dixon R, Moselen E, Osborne RH. Health literacy amongst health professional university students: a study using the Health Literacy Questionnaire. Education Sciences. 2017 Jun;7(2):54. org/10.3390/educsci7020054

29. Juvinyà-Canal D, Suñer-Soler R, Porquet AB, Vernay $M$, Blanchard $H$, Bertran-Noguer $C$. Health Literacy among Health and Social Care University Students. International journal of environmental research and public health. 2020 Jan;17(7):2273. doi:10.3390/ijerph17072273

30. McCleary-Jones V. A systematic review of the literature on health literacy in nursing education. Nurse educator. 2016 Mar 1;41(2):93-7.doi.93-97.10.1097/NNE.0000000000000204

31. Ozen N, Bal Ozkaptan B, Coskun S, Terzioglu F. Health literacy of nursing students and its effective factors. In Nursing forum 2019 Jul (Vol. 54, No. 3, pp. 396-402). org/10.1111/nuf.12346

32. Dag S, Abic A. Determining Healthy Lifestyle Behaviours of Nursing Students. International Journal of Basic and Clinical Studies (IJBCS) 2016; 5(1): 37-43

33. Holt KA, Overgaard D, Engel LV, Kayser L. Health literacy, digital literacy and eHealth literacy in Danish nursing students at entry and graduate level: a cross sectional study. BMC nursing. 2020 Dec;19:1-2. org/10.1186/s12912-020-00418-w

34. Balmer D, King A, Moloney W, Moselen E, Dixon R. Nursing students and health literacy: The effect of region and programme level. Nurse education in practice. 2020 Jan 1;42:102688. org/10.1016/j.nepr.2019.102688

35. Bulfone G, Maurici M, Vellone E, Macale L, Alvaro R. Health habits of nursing students: A longitudinal study of health perceptions and health habits. Journal of Clinical Nursing. 2020 Nov;29(21-22):434957.doi.org/10.1111/jocn. 15473 